\title{
Association of screen time with parent- reported cognitive delay in preschool children of Kerala, India
}

\author{
Jijo Joseph John ${ }^{1}$, Reny Joseph ${ }^{2 *}$ D, Alice David ${ }^{3}$, Ann Bejoy $^{3}$, Kalyan Varghese George ${ }^{3}$ and Lisa George ${ }^{3}$
}

\begin{abstract}
Background: Screen use is increasing rapidly among preschool children and excess screen use in these children has been associated with cognitive side effects and speech delay. We undertook this study to estimate the risk associated with screen time in children, parental supervision, and parent-reported cognitive development among preschool children aged 2-5 years.

Methods: A cross-sectional study was done between July 2019 and January 2020 involving parents of all students aged 2-5 years, attending 2 kindergarten schools in Thiruvalla using a self-administered questionnaire. Parents also used the Werner David Development pictorial scale (WDDPS), a screening tool to report cognitive development. The schools were sampled based on convenience.

Results: Of the 189 children included in the study, 89.4\% had excess screen use ( $>1 \mathrm{~h}$ per day) and the average use was 2.14 h. $45.0 \%$ of parents supervised screen use inconsistently (self-reported). Meal-time screen use (OR 3.8, $95 \% \mathrm{Cl} 1.3-10.8$ ), receiving screen on demand (OR 3.7, 95\% Cl 1.2-11.3), and using devices other than computers (OR 6.5, 95\% Cl 1.6-26.8) were significantly associated with excess screen use in pre-school children. Similarly, those children with inconsistently supervised screen time were significantly more likely to have suspected deficits in attention (OR 3.2, 95\% Cl 1.3-8.2), intelligence (OR 4.1, 95\% Cl 1.3-13.3), and social skills (OR 15.3, 95\% Cl 1.9-121.2), compared to children whose screen use was consistently supervised.

Conclusion: Screen time in the majority of preschool children is above the recommended limits, and inconsistent supervision by parents was seen in almost half of the study participants. Inconsistently supervised screen time is associated with suspected cognitive delays in children.
\end{abstract}

Keywords: Screen use, Preschool children, Cognitive delay, Parental supervision

\section{Introduction}

Digital media and screens are a ubiquitous part of our daily lives and children in today's world are digital natives. The American Academy of Pediatrics (AAP) and the World Health Organization (WHO) have recommended limiting screen use to less than $1 \mathrm{~h}$ in children 2 to 5 years of age, along with an emphasis on selecting

* Correspondence: drrenyj@gmail.com

${ }^{2}$ MGM Muthoot Hospital, Kozhencherry, Kerala, India

Full list of author information is available at the end of the article high-quality programs, supervised viewing, and coviewing with the child and avoiding screen time in children younger than 18 months (except for video chatting) $[1,2]$. Screen time refers to time spent on any digital media such as television, smartphones, computer, tablets, gaming consoles, etc. India, in the recent past, has seen a major increase in the amount and types of media being consumed. According to a McKinsey report, India is one of the fastest-growing markets for digital consumers, second only to China [3]. 
The Covid-19 pandemic and the associated lockdown have confined children to their homes and has resulted in an exponential increase in screen use in children [4]. Children under 5 years are a vulnerable population as this is the age where maximum brain growth occurs and increased screen time is associated with adverse neurocognitive outcomes and speech delay [5]. Recent studies with functional cerebral MRI have shown an association between increased screen use and decreased microstructural integrity of brain white matter tracts which supports language and literacy skills [6]. Excess television use in toddlers and preschool children has been demonstrated to have a negative impact on the cognitive, language, and motor skills in this age group [7, 8]. Recent studies with touchscreen devices have also shown excess use in preschool age to be associated with emotional problems, anxiety/depressive symptoms, attention problems, and aggressive behavior, without affecting language delays [9].

Parents are the teachers, facilitators, and gate-keepers of a young child's media consumption. Screen media parenting practices refer to goal-directed parental interactions with the child, to influence the child's screen media use [10]. According to a study published by Douglas Gentile et.al, four types of parental monitoring help in healthy screen habits in children - co-viewing with the child, restricting time spent on media, restricting content viewed on-screen, and active mediation- offering opinions on media content, educating the child about the purpose of various media such as advertising and encouraging them to apply practical aspects of the contents viewed to daily life [11].

Only a few studies from India have evaluated screen use in preschool children [12, 13], and as far as we know, no study in India has studied the association of screen time with cognitive delays and parental mediation during screen use. Hence this study was undertaken to estimate the risk associated with screen time in children, parental supervision, and parent-reported cognitive development among preschool children aged 2-5 years.

\section{Methods}

A cross-sectional study was done between July 2019 and January 2020, of parents of all students aged 2-5 years, attending 2 kindergarten schools in Thiruvalla, using a self-administered questionnaire. Parents also used the Werner David Development pictorial scale (WDDPS), a screening tool to assess cognitive development. The schools were sampled based on convenience. These schools are attended by children from upper middle class and middle-class families. Parents who refused to give consent were excluded from the study. Approvals from the Institutional Research Board and Ethics Committee of the hospital were obtained.

\section{Measures}

a. Demographics - Information regarding age and sex of the child, parental education and occupation, the pattern of screen use at home, and children's involvement in other activities were obtained. The socio-economic status of the family was calculated using the modified Kuppuswamy scale, revised for 2017 using real-time update tool, which is a socio-economic scoring scale, validated for use in India [14].

b. Parental Supervision- Parental practices regarding the child's screen viewing, such as restricting screen time, supervising content, and co-viewing with the child, were obtained using a self-reported questionnaire. Co-viewing (shared screen), implies interacting with the child and asking questions related to the content viewed [1]. Parents responded to "how often do you supervise your child's screen use" as all the time (1), some of the time (2), and never (3). Self-reported parental supervision was categorized as consistent and inconsistent, with responses 2 and 3 being considered inconsistent.

c. Cognitive development: Parents were asked to fill the WDDPS scale [Appendix-supplementary file 1). WDDPS is taken from the book by David Werner titled ' Disabled Village Children- a guide for community health workers, rehabilitation workers and families', published by the Hesperian Foundation and adapted for India by the Voluntary Health Association of India. This chart has also been mentioned in the book entitled 'Family care for children with disabilities- Practical guidance for frontline workers in Low and Middle-income countries', which has been endorsed by USAID, World Learning and Partnership for every child [15]. There are two charts, one representing physical development and one representing mental and social development. We used the mental and social development chart, which is a screening tool, with age-appropriate pictorial representation of cognitive milestones. This scale assessed 6 components (domains) such as communication, social skills, selfcare, attention span, play, and intelligence based on the achievement of an essential skill per domain, at ages of 3 months, 6 months, 9 months, 1 year, 2 years, 3 years and 5 years [16]. Children who had not achieved the age-appropriate milestone were considered to have a suspected delay. We also asked parents about their perception of speech delay and social interaction in their child.

Printed questionnaires were sent home with the students along with an information sheet about the study and consent form, and completed response sheets were 
collected back from the students after 1 week. Parents filled the questionnaires at home.

\section{Statistical methods}

Descriptive statistics comprising of frequencies and percentages were calculated. Proportions were compared using Fisher's exact test. Estimates of risk were calculated using Odds Ratio with 95\% confidence interval, where the response variables were 'excess screen time' or 'inconsistent supervision' depending on the question. The explanatory variables include all determinants and social and development related factors that were significantly different. A logistic regression model was built with the determinants alone. Data was analyzed using SAS University Edition.

\section{Results}

Of all the 240 children surveyed, only 189 (79\%) were included in the final analysis. Reasons for exclusion include, below 2 years of age (7\%), lack of consent (8.3\%), and incomplete forms (10\%). Among the ones included, 89.9\% viewed some form of screen more than the recommended $1 \mathrm{~h}$ per day limit. The mean \pm SD being $2.1 \mathrm{~h} \pm 0.4 \mathrm{~h}$.

Demographic data for the study sample are included in Table 1. Screen time was not associated with the child's gender $(p=0.91)$, mother's education $(p=0.16)$, or with the mother's occupation $(p=0.32)$. Similarly, supervised screen viewing was not significantly different for gender $(p=0.69)$, the mother's education $(p=0.18)$, or the mother's occupation $(p=0.50)$. Every child in our study belonged to an upper middle-class family.

We considered various factors as potential determinants of screen time and supervised screen viewing, including age at introduction, ownership of the device, types of screen, content viewed, time of use, the context of screen used, and forms of supervision as seen in Tables 2 and 3. Risk estimates of those factors that were found to be significant are given in Table 4. Factors that were significantly associated with excess screen time include viewing during mealtime $(p=0.01)$ and allowing the child to use a screen whenever the child demanded $(p=0.01)$, with an estimated risk of 3.4 (OR 3.4, 95\% CI 1.3-8.9), and 3.7 (OR 3.7, 95\% CI 1.3-10.8) times respectively. Using the screen only up to the recommended time of $1 \mathrm{~h}$ per day was associated with viewing on a computer $(p=0.05)$, planning the time when the child could view $(p=0.04)$, and co-viewing $(p=0.01)$. On adjusting for other factors, not using computers, mealtime viewing, and on-demand viewing emerged as independent risk factors of excess screen time with a risk estimate of 6.5 (OR 6.5, 95\% CI 1.6-26.8), 3.8 (OR 3.8, 95\% CI 1.3-10.8) and 3.7 (OR 3.7, 95\% CI 1.2-11.3) times respectively.

Inconsistent supervision was associated with the child having a device of his or her own $(p=0.05)$, when viewing on devices other than a computer $(p=0.06)$, during mealtime $(p=0.07)$, when permitted to view when the child demanded it $(p=0.01)$, when viewing was not planned $(p=0.01)$, when no time limit was set $(p=0.02)$ and when co-viewing was not involved $(p=0.01)$. However on adjusting for all significant factors, only using screen devices other than a computer, unplanned viewing and lack of co-viewing emerged as independent risk factors for inconsistent supervision, with an estimated risk of 5.1 (OR 5.1, 95\% CI 1.3-19.6), 2.6 (OR 2.6, 95\% CI 1.1-6.0) and 7.8 (OR 7.8, 95\% CI 3.3-18.2) times respectively.

We also considered various factors that could potentially be the effect of excess screen time or inconsistent parental supervision while viewing, including various activities and developmental markers as per WDDPS. Risk estimates of potential effects of excess screen time and inconsistent supervision are given in Table 5. While none of the factors were associated with excess screen time, almost all of them were associated with inconsistent parental supervision. Inconsistent supervision is associated with children being involved in physical activity for less than $1 \mathrm{~h}$ per day $(p=0.01)$, not drawing $(p=$ $0.04)$ and not being interested in other activities $(p=$ 0.02 ) with a risk estimate of 2.3 (OR 2.3, 95\% CI 1.3-4.2), 1.9 (OR 1.9, 95\% CI 1.0-3.5), and 2.9(OR 2.9, 95\% CI 1.2-6.8) times respectively.

Moreover, inconsistent supervised viewing is associated with suspected cognitive delays, as per WDDPS, such as delay in attention $(p=0.01)$, intelligence $(p=$ $0.02)$, and in social interactions $(p<0.005)$, with a risk estimate of 3.2 (OR 3.2, 95\% CI 1.3-8.2), 4.1 (OR 4.1, 95\% CI 1.3-13.3) and 15 (OR 15.3, 95\% CI 1.9-121.2) times when compared to children whose screen use are consistently supervised respectively.

Table 1 Socio demographic characteristics associated with screen time and supervision

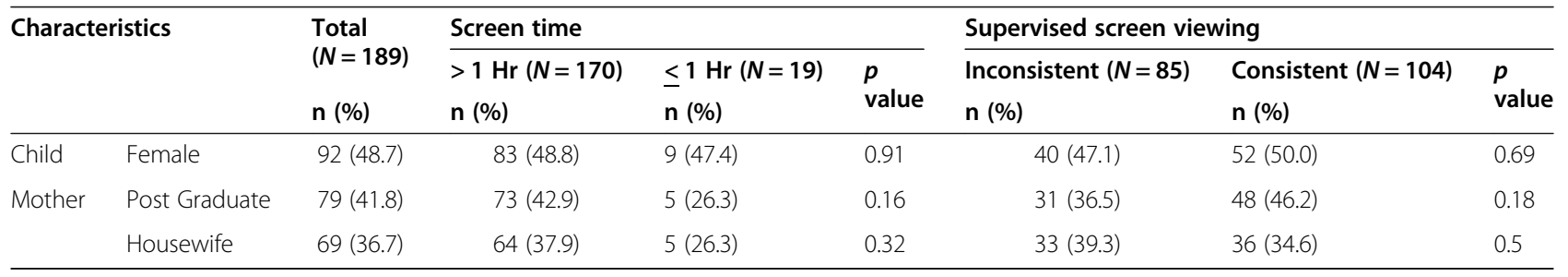


Table 2 Potential determinants of screen time \& parental supervised screen viewing

\begin{tabular}{|c|c|c|c|c|c|c|c|c|}
\hline \multirow{2}{*}{\multicolumn{2}{|c|}{ Characteristics }} & \multirow{3}{*}{$\begin{array}{l}\text { Total } \\
(N=189) \\
\text { n (\%) }\end{array}$} & \multicolumn{3}{|c|}{ Screen time } & \multirow{2}{*}{\multicolumn{3}{|c|}{ Supervised screen viewing }} \\
\hline & & & \multirow{2}{*}{$\begin{array}{l}>1 \mathrm{Hr} \\
(N=170) \\
n(\%)\end{array}$} & \multirow{2}{*}{$\begin{array}{l}\leq 1 \mathrm{Hr}(N=19) \\
\mathrm{n}(\%)\end{array}$} & \multirow{2}{*}{$\begin{array}{l}p \\
\text { value }\end{array}$} & & & \\
\hline & & & & & & $\begin{array}{l}\text { Inconsistent }(N=85) \\
\mathrm{n}(\%)\end{array}$ & $\begin{array}{l}\text { Consistent }(N=104) \\
\mathrm{n}(\%)\end{array}$ & $\begin{array}{l}p \\
\text { value }\end{array}$ \\
\hline Age at Introduction & $\leq 1$ year & $13(6.9)$ & $13(7.7)$ & $0(0.0)$ & 0.37 & $6(7.1)$ & $7(6.7)$ & 1 \\
\hline Own & Own Device & $14(7.4)$ & $12(7.1)$ & $2(10.5)$ & 0.64 & $10(11.8)$ & $4(3.9)$ & $0.05^{*}$ \\
\hline \multirow[t]{5}{*}{ Type of Screen } & TV & $145(76.7)$ & $131(77.1)$ & $14(73.7)$ & 0.78 & $63(74.1)$ & $82(78.9)$ & 0.49 \\
\hline & Mobile & $98(51.9)$ & $90(52.9)$ & $8(42.1)$ & 0.47 & $48(56.5)$ & $50(48.1)$ & 0.31 \\
\hline & Tablet & $15(7.9)$ & $12(7.1)$ & $3(15.8)$ & 0.18 & $6(7.1)$ & $9(8.7)$ & 0.79 \\
\hline & Video Game & $2(1.1)$ & $2(1.2)$ & $0(0.0)$ & 1.00 & $0(0.0)$ & $2(1.9)$ & 0.50 \\
\hline & Computer & $15(7.9)$ & $11(6.5)$ & $4(21.1)$ & $0.05^{*}$ & $3(3.5)$ & $12(11.5)$ & 0.06 \\
\hline \multirow[t]{4}{*}{ Content Viewed } & Gaming & $26(13.8)$ & $24(14.1)$ & $2(10.5)$ & 1.00 & $11(12.9)$ & $15(14.4)$ & 0.83 \\
\hline & Cartoon & $156(82.5)$ & $142(83.5)$ & $14(73.7)$ & 0.34 & $66(77.7)$ & $90(86.5)$ & 0.13 \\
\hline & YouTube & $49(25.9)$ & $42(24.7)$ & $7(36.8)$ & 0.27 & $23(27.1)$ & $26(25.0)$ & 0.87 \\
\hline & Other Devices & $14(7.4)$ & $12(7.1)$ & $2(10.5)$ & 0.64 & $5(5.9)$ & $9(8.7)$ & 0.58 \\
\hline \multirow[t]{2}{*}{ Time of Use } & $\leq 1 \mathrm{Hr}$ Before Bed & $112(59.3)$ & $99(58.2)$ & $13(68.4)$ & 0.47 & $53(62.4)$ & $59(56.7)$ & 0.46 \\
\hline & Meal Time & $137(72.5)$ & $128(75.3)$ & $9(47.4)$ & $0.01^{*}$ & $56(65.9)$ & $81(77.9)$ & 0.07 \\
\hline \multirow[t]{5}{*}{ Context of Screen Use } & On Demand & $102(54.0)$ & $97(57.1)$ & $5(26.3)$ & $0.01^{*}$ & $53(62.4)$ & $49(47.1)$ & $0.04^{*}$ \\
\hline & Reward & $32(16.9)$ & $29(17.1)$ & $3(15.8)$ & 1.00 & $12(14.1)$ & $20(19.2)$ & 0.44 \\
\hline & Pacify & $26(13.8)$ & $25(14.7)$ & $1(5.3)$ & 0.48 & $14(16.5)$ & $12(11.5)$ & 0.40 \\
\hline & Tantrums & $110(58.2)$ & $101(59.4)$ & $9(47.4)$ & 0.34 & $50(58.8)$ & $60(57.7)$ & 0.88 \\
\hline & Planned & $41(21.7)$ & $33(19.4)$ & $8(42.1)$ & $0.04^{*}$ & $11(12.9)$ & $30(28.9)$ & $0.01 *$ \\
\hline \multirow[t]{6}{*}{ Supervision } & Consistent Supervision & $104(55.0)$ & $95(55.9)$ & $9(47.4)$ & 0.63 & N/A & N/A & N/A \\
\hline & Co-view & $136(72.0)$ & $44(25.9)$ & $9(47.4)$ & 0.06 & & & \\
\hline & Monitor - Content & $176(93.1)$ & $159(93.5)$ & $17(89.5)$ & 0.62 & & & \\
\hline & Monitor - Time & $184(97.4)$ & $166(97.7)$ & $18(94.7)$ & 0.41 & & & \\
\hline & Set Time Limit & $135(71.4)$ & $128(75.3)$ & $19(100.0)$ & $0.01^{*}$ & & & \\
\hline & Screen Free Interval & $137(72.5)$ & $125(73.5)$ & $12(63.2)$ & 0.42 & & & \\
\hline Screen Time & $>1$ Hour & $170(89.9)$ & N/A & N/A & N/A & $75(88.24)$ & $95(91.35)$ & 0.63 \\
\hline
\end{tabular}

\section{Discussion}

Early childhood is a period of significant cognitive and behavioral development. Cognitive skills that help children to understand and process information, interact with their environment, and use logic to understand mathematical and scientific processes are garnered during this time [17]. Much like other habits, viewing habits that begin in infancy persist into childhood [18]. Pediatric societies all over the world recommend limiting screen use among preschool children and emphasize on consistent parental mediation to offset the harmful effects of screen. However, adherence to these guidelines is poor and shows a diminishing trend $[1,19,20]$. This study builds on previous research, evaluating the determinants of excess screen use and inconsistent parental supervision of screen viewing and its association with suspected cognitive delays among young children in the Indian context.
According to 2 other studies from India, less than 20\% of preschool children use a screen for less than $1 \mathrm{~h}$ a day $[12,13]$. Our study demonstrated similarly, with an average screen use of $2.1 \mathrm{~h}$ per day and $89.9 \%$ exceeding the AAP recommendations. Similar to most published literature, we found that the commonest screen used was TV (76.7\%), and the type of content most watched were cartoons $(82.5 \%)$ [12, 21]. We found children who used devices other than a computer were 6.5 times more likely to have excess screen time. Also, children who did not have a structured screen use plan and a set time limit were three to four times more likely to have excess screen time. Most parents provided screen time on demand (54.0\%) and during mealtimes (72.5\%). Irrespective of other factors, these two factors were significantly associated with excess screen use. Interestingly other studies have reported a much lower prevalence of mealtime screen use $(22-50 \%)$ [22, 23], and most pediatric 
Table 3 Cognitive development - screen time \& parental supervision

\begin{tabular}{|c|c|c|c|c|c|c|c|c|}
\hline \multirow[t]{3}{*}{ Characteristics } & & \multirow{3}{*}{$\begin{array}{l}\text { Total } \\
(N= \\
189) \\
\text { n (\%) }\end{array}$} & \multicolumn{3}{|c|}{ Excess screen time } & \multicolumn{3}{|c|}{ Supervised screen viewing } \\
\hline & & & \multirow{2}{*}{$\begin{array}{l}>1 \mathrm{Hr}(N= \\
170) \\
\mathrm{n}(\%)\end{array}$} & \multirow{2}{*}{$\begin{array}{l}\leq 1 \mathrm{Hr}(\mathrm{N}= \\
19) \\
\mathrm{n}(\%)\end{array}$} & & & & \\
\hline & & & & & $\begin{array}{l}p \\
\text { value }\end{array}$ & $\begin{array}{l}\text { Inconsistent }(N= \\
85) \\
\mathrm{n}(\%)\end{array}$ & $\begin{array}{l}\text { Consistent }(N= \\
104) \\
\mathrm{n}(\%)\end{array}$ & $\begin{array}{l}p \\
\text { value }\end{array}$ \\
\hline \multirow[t]{6}{*}{ Activity } & $\begin{array}{l}\text { Physical Activity > } 1 \\
\mathrm{Hr}\end{array}$ & $\begin{array}{l}122 \\
(64.6)\end{array}$ & $108(63.5)$ & $14(73.7)$ & 0.46 & $46(54.1)$ & $76(73.1)$ & $0.01^{*}$ \\
\hline & Draw & $\begin{array}{l}126 \\
(66.7)\end{array}$ & $113(66.5)$ & $13(68.4)$ & 1.00 & $50(58.8)$ & $76(73.1)$ & $0.04^{*}$ \\
\hline & Craft & $54(28.6)$ & $49(28.8)$ & $5(26.3)$ & 1.00 & $24(28.2)$ & $30(28.9)$ & 1.00 \\
\hline & $\begin{array}{l}\text { Interact - } \\
\text { Playmates }\end{array}$ & $\begin{array}{l}134 \\
(70.9)\end{array}$ & $123(72.4)$ & $11(57.9)$ & 0.19 & $63(74.1)$ & $71(68.3)$ & 0.42 \\
\hline & $\begin{array}{l}\text { Interact - Older } \\
\text { Family }\end{array}$ & $86(45.5)$ & $80(47.1)$ & $6(31.6)$ & 0.23 & $37(43.5)$ & $49(47.1)$ & 0.66 \\
\hline & Other Activity & $32(16.9)$ & $29(17.1)$ & $3(15.8)$ & 1.00 & $8(9.4)$ & $24(23.1)$ & $0.02^{*}$ \\
\hline \multirow{6}{*}{$\begin{array}{l}\text { Suspected } \\
\text { Cognitive Delay as per } \\
\text { WDDPS }\end{array}$} & Communication & $18(9.5)$ & $17(10.0)$ & $1(5.3)$ & 1.00 & $10(11.8)$ & $8(7.7)$ & 0.46 \\
\hline & Social Interaction & $12(6.3)$ & $10(5.9)$ & $2(10.5)$ & 0.34 & $11(12.9)$ & $1(1.0)$ & $<$ \\
\hline & Self-Care & $7(3.7)$ & $6(3.5)$ & $1(5.3)$ & 0.53 & $3(3.5)$ & $4(3.9)$ & 1.00 \\
\hline & Attention & $23(12.2)$ & $21(12.4)$ & $2(10.5)$ & 1.00 & 16 (18.8) & $7(6.7)$ & $0.01^{*}$ \\
\hline & Play & $13(6.9)$ & $12(7.1)$ & $1(5.3)$ & 1.00 & $9(10.6)$ & $4(3.9)$ & 0.09 \\
\hline & Intelligence & $16(8.5)$ & $14(8.2)$ & $2(10.5)$ & 0.67 & $12(14.1)$ & $4(3.9)$ & $0.02^{*}$ \\
\hline
\end{tabular}

${ }^{*} p \leq 0.05$

societies recommend avoiding screen use during meal times $[1,24]$. A recently published study from Lithuania also found a similar significant association between mealtime screen use and excess screen use among children aged 2-5 years [22].

Our study had very few children (6.9\%) who started viewing before the age of 1 year, unlike reported literature which has shown that significant media exposure starts from around 6 months of age [25]. It has been shown that children comprehend child-directed television only from around 2 years of age [22]. Exposure to adult-directed television early in life, as well as high background television exposure, has negative correlations with the child's executive functioning and cognitive development [26]. Similar effects are not seen when infants viewed child-oriented media [26].

The cognitive impact of screen use on the very young child depends not only on the quantity and the social context of media used but also on the quality of programs [25]. Active media (video games/completing homework on the computer) have been shown to improve academic performance and reduce school absenteeism [27]. Passive screen time involving receiving passive screen-based information is harmful especially for preschool children, except for certain age-appropriate programs such as 'Sesame Street' [28]. It is of concern that active screen use was seen in only about $13 \%$ of the children in our study and cartoon viewing was almost ubiquitous. Moreover, the pacing of

Table 4 Risk estimates of potential determinants of screen time \& supervision

\begin{tabular}{|c|c|c|c|c|}
\hline \multirow[t]{2}{*}{ Characteristics } & \multicolumn{2}{|c|}{ Excess screen time } & \multicolumn{2}{|c|}{ Inconsistent supervision } \\
\hline & OR $(95 \% \mathrm{Cl})$ & Adj. OR (95\% Cl) & OR $(95 \% \mathrm{Cl})$ & Adj. OR (95\% Cl) \\
\hline Own Device & $1.5(0.3-7.5)$ & NS & $0.3(0.09-1.0)$ & NS \\
\hline Not Computer & $3.9(1.1-13.1)^{*}$ & $6.5(1.6-26.8)^{*}$ & $3.6(1.0-13.1)$ & $5.1(1.3-19.6)^{*}$ \\
\hline Meal Time & $3.4(1.3-8.9)^{*}$ & $3.8(1.3-10.8)^{*}$ & $0.6(0.3-1.0)$ & $0.5(0.2-1.0)^{*}$ \\
\hline On Demand & $3.7(1.3-10.8)^{*}$ & $3.7(1.2-11.3)^{*}$ & $1.9(1.0-3.3)$ & NS \\
\hline Not Planned & $3.0(1.1-8.1)^{*}$ & NS & $2.7(1.3-5.8)$ & $2.6(1.1-6.0)^{*}$ \\
\hline No Time limit & N/A & NS & $2.1(1.1-4.3)$ & NS \\
\hline Not Co-view & $2.6(1.0-6.8)^{*}$ & NS & $7.3(3.2-16.7)$ & $7.8(3.3-18.2)^{*}$ \\
\hline
\end{tabular}

NS not significant, N/A not applicable 
Table 5 Risk estimates of potential effects of screen time \& supervision

\begin{tabular}{llll}
\hline Characteristics & & $\begin{array}{l}\text { Excess screen time } \\
\text { OR (95\% Cl) }\end{array}$ & $\begin{array}{l}\text { Inconsistent supervision } \\
\text { OR (95\% Cl) }\end{array}$ \\
\hline Activities & Physical Activity $<1 \mathrm{Hr}$ & $1.6(0.6-4.7)$ & $2.3(1.3-4.2)^{*}$ \\
& Not Drawing & $1.1(0.4-3.0)$ & $1.9(1.0-3.5)^{*}$ \\
& No other activities & $0.9(0.3-3.3)$ & $2.9(1.2-6.8)^{*}$ \\
Cognitive Delay as per WDDPS & Social Interaction & $0.5(0.1-2.6)$ & $15.3(1.9-121.2)^{*}$ \\
& Attention & $1.2(0.3-5.6)$ & $3.2(1.3-8.2)^{*}$ \\
\hline
\end{tabular}

${ }^{*} p<0.05$

content in shows designed for children is extremely rapid. This auditory and visual over-stimulation may prime children to expect similar fast-paced activities in daily life, and the lack thereof can lead to inattention $[29,30]$.

Parent-reported suspected cognitive delay measured using the WDDPS was not found to be associated with excess screen use. This is probably because of the simplicity of the screening tool used, the number of children with suspected cognitive delay being low and the majority of the children (89.9\%) having excess screen time. Various studies have shown a strong association between increased television use ( $>2 \mathrm{~h}$ per day), and significant language delays $[19,28,31]$. In a study from Taiwan, Lin et.al demonstrated a significantly higher cognitive delay among children with increased television exposure (OR 3.9, 95\% CI 1.4-5.9) [7]. In contrast to our study, a recent systematic review and meta-analysis revealed that children with excess screen time were at a higher risk of delayed language development, learning problems (language and mathematics), and reading problems [32].

Apart from screen time, we also studied the four types of parental supervision, since supervised viewing and coviewing has also been recommended by AAP, including active supervision, co-viewing, restricting time spent on screen, and restricting the content $[10,11]$. In our study, while $97.4 \%$ of the parents employed restrictive supervision and set rules regarding screen time and content, only about $28 \%$ of parents co-viewed media content with their child. Moreover, only 55\% were able to consistently supervise children during screen use. We examined if the same factors that determine screen time would also determine supervision. In the univariate analysis, children who had their own device, who used screens other than a computer, got screen on demand, and had unplanned screen time were significantly more likely to have inconsistent parental supervision. These factors are similar to the ones that determine excess screen time. Independent factors include using devices other than a computer, not having a structured plan, and not coviewing.

There is growing evidence to suggest that children learn the most from screens when caregivers are actively engaged in viewing content with them [33]. Suspected cognitive delays were reported by parents using WDDPS among those who had inconsistent supervision. These children were 15.3 times more likely to have a delay in social interactions, 3.2 times more likely to have attention deficit, and 4.1 times more likely to have intelligence delay.

We also considered the association of inconsistent supervision on routine activities and found that inconsistently supervised children were 2.3 times more likely to have less than $1 \mathrm{~h}$ of physical activity, 1.9 times more likely not to draw, and 2.9 times more likely not to be interested in other activities. Though a cross-sectional study of more than 8000 US children did not find any significant association between screen time and physical activity [34], data regarding parental supervision during screen use and correlation with physical activity, and cognitive delay was lacking.

There are certain limitations to our study. Attitude and determinants of parental screen time and effect of sibling screen use were not assessed. Cognitive development and speech delay was assessed based on a parental questionnaire and a formal assessment was not done. The scale used to assess cognitive development was not validated for the sample studied. The use of a parental questionnaire may have led to recall bias and the veracity of the responses could not be ascertained. Also as the children included in our study were all from the upper middle class, the results might not be generalizable to the entire population. Moreover, the lack of association of excess screen time with various factors studied may be due to the low prevalence of those who watch less than $1 \mathrm{~h}$ a day. This study looked at associations between screen use and cognitive delays and direct causal relationships have not been ascertained.

This study throws light on the importance of consistent parental supervision, avoidance of screen during meal times, and a structured media plan for preschool children. Larger population-based surveys are the need of the hour to understand the effects of this growing pandemic on this vulnerable population. 


\section{Conclusions}

Screen use in the sample population is much higher than the recommended daily limit of $1 \mathrm{~h}$ per day. Avoiding screen use with meal times and giving screen to the child only in a planned manner are practical tips to prevent excess screen use in children. Restricting screen use to computers may give more control for the parents to supervise screen use in children. Inconsistent parental supervision is suspected to affect cognitive outcomes of preschool children.

\section{Supplementary Information}

The online version contains supplementary material available at https://doi. org/10.1186/s12887-021-02545-y.

Additional file 1. Questionnaire used in the study including Werner David Developmental Pictorial Scale (WDDPS).

\section{Abbreviations}

WDDPS: Werner David Developmental Pictorial Scale; AAP: American Academy of Pediatrics; WHO: World Health Organization; MRI: Magnetic resonance imaging; KG: Kindergarten; SD: Standard deviation

\section{Acknowledgements}

Dr. Piyush Gupta, for reviewing the manuscript.

\section{Authors' contributions}

Study concept and design: JJ, AD. Acquisition, analysis, or interpretation of data: JJ, RJ, AD, AB, KG, LG. Drafting of the manuscript: RJ, JJ, AD. Critical revision of the manuscript for important intellectual content: All authors. Statistical analysis: AD. All authors have read and approved the final draft of the manuscript.

\section{Funding}

No funding was received from the institution/extraneous sources for the conduct of this study.

\section{Availability of data and materials}

The dataset used/analyzed during the current study is available from the corresponding author on reasonable request.

\section{Ethics approval and consent to participate}

Institutional ethics Committee of Believer's Church Medical College Hospital obtained prior to study (Ref: IEC/2019/06/104). Written consent was obtained from the parents prior to enrolling the child in the study.

\section{Consent for publication}

Not applicable.

\section{Competing interests}

All authors declare they have no competing interests in the conduct and publication of this study.

\section{Author details}

'Department of Pediatrics, Believer's Church Medical College, Thiruvalla, Kerala, India. ${ }^{2}$ MGM Muthoot Hospital, Kozhencherry, Kerala, India. ${ }^{3}$ Believer's Church Medical College, Thiruvalla, Kerala, India.

Received: 28 September 2020 Accepted: 8 February 2021 Published online: 11 February 2021

\section{References}

1. Council on communications and media. Media and Young Minds. Pediatrics. 2016;138(5):e20162591.

2. World Health Organization. Guidelines on physical activity, sedentary behavior and sleep for children under 5 years of age: web annex: evidence profiles. World Health Organization; 2019. Available from: https://apps.who. int/iris/bitstream/handle/10665/311664/9789241550536-eng.pdf

3. Digital-India-technology-to-transform-a-connected-nation-In-brief.pdf [Internet]. [cited 2020 Mar 31]. Available from: https://www.mckinsey.com/ / media/McKinsey/Business/Functions/McKinsey/Digital/Ourlnsights/DigitalIndia-technology-to-transform-a-connected-nation-In-brief.ashx.

4. Survey Shows Parents Alarmed as Kids' Screen Time Skyrockets During COVID-19 Crisis. Parents Together. 2020 [cited 2020 Dec 29]. Available from: https://parents-together.org/survey-shows-parents-alarmed-as-kids-screentime-skyrockets-during-covid-19-crisis/

5. Zimmerman FJ, Christakis DA. Children's television viewing and cognitive outcomes: a longitudinal analysis of national data. Arch Pediatr Adolesc Med. 2005:159(7):619-25.

6. Hutton JS, Dudley J, Horowitz-Kraus T, DeWitt T, Holland SK. Associations between screen-based media use and brain white matter integrity in preschool-aged children. JAMA Pediatr. 2020;174(1):e193869.

7. Lin L-Y, Cherng R-J, Chen Y-J, Chen Y-J, Yang H-M. Effects of television exposure on developmental skills among young children. Infant Behav Dev. 2015;38:20-6

8. Felix E, Silva V, Caetano M, Ribeiro MW, Fidalgo TM, Rosa Neto F, et al. Excessive screen media use in preschoolers is associated with poor motor skills. Cyberpsychol Behav Soc Netw. 2020;23(6):418-25.

9. Lin H-P, Chen K-L, Chou W, Yuan K-S, Yen S-Y, Chen Y-S, et al. Prolonged touch screen device usage is associated with emotional and behavioral problems, but not language delay, in toddlers. Infant Behav Dev. 2020;58:101424.

10. O'Connor TM, Hingle M, Chuang R-J, Gorely T, Hinkley T, Jago R, et al. Conceptual understanding of screen media parenting: report of a working group. Child Obes. 2013.

11. Gentile DA, Reimer RA, Nathanson Al, Walsh DA, Eisenmann JC. Protective effects of parental monitoring of children's media use: a prospective study. JAMA Pediatr. 2014;168(5):479-84.

12. Shirley S, Kumar S. A study on screen time use in children between 24 to 60 months of age in Tamilnadu, India. Int J Contemp Pediatr. 2019;6:2582.

13. Shah RR, Fahey NM, Soni AV, Phatak AG, Nimbalkar SM. Screen time usage among preschoolers aged 2-6 in rural Western India: a cross-sectional study. J Fam Med Prim Care. 2019;8(6):1999-2002.

14. Modified Kuppuswamy Scale [cited 2020 Dec 17]. Available from: http:// www.ihatepsm.com/blog/modified-kuppuswamy-scale

15. Sammon EM, Burchell G. Family care for children with disabilities: practical guidance for frontline workers in low- and middle-income countries. https://bettercarenetwork.org/sites/default/files/FamilyCareGuidance_508. pdf. Accessed 27 Jan 2020.

16. Disabled Village Children - chapter 5 [cited 2020 Apr 7]. Available from: https://www.dinf.ne.jp/doc/english/global/david/dwe002/dwe00207.html

17. The Child's Conception of Space / by Jean Piaget and Bärbel Inhelder ; translated from the French by F.J. Langdon \& J.L. Lunzer. - Version details [Internet]. Trove. [cited 2020 Jun 21]. Available from: https://trove.nla.gov.au/ version/20942616

18. Certain LK, Kahn RS. Prevalence, correlates, and trajectory of television viewing among infants and toddlers. Pediatrics. 2002;109(4):634-42.

19. Screen time and young children: Promoting health and development in a digital world. Paediatr Child Health. 2017;22(8):461-8.

20. Bozzola E, Spina G, Ruggiero M, Memo L, Agostiniani R, Bozzola M, et al. Media devices in pre-school children: the recommendations of the Italian pediatric society. Ital J Pediatr. 2018;44(1):69.

21. Goh SN, Teh LH, Tay WR, Anantharaman S, van Dam RM, Tan CS, et al. Sociodemographic, home environment and parental influences on total and device-specific screen viewing in children aged 2 years and below: an observational study. BMJ Open. 2016;6(1):e009113.

22. Jusienè R, Urbonas V, Laurinaitytè I, Rakickienè L, Breidokienẻ R, Kuzminskaitė $M$, et al. Screen Use During Meals Among Young Children: Exploration of Associated Variables. Medicina (Mex). 2019;55(10) [cited 2020 Jun 21]. Available from: https://www.ncbi.nlm.nih.gov/pmc/articles/PMC6843261/.

23. Dinleyici M, Carman KB, Ozturk E, Sahin-Dagli F. Media use by children, and parents' views on children's media usage. Interact J Med Res. 2016;5(2):e18.

24. Canadian Paediatric Society DHTF Ottawa, Ontario. Screen time and young children: promoting health and development in a digital world. Paediatr Child Health. 2017:22(8):461-8.

25. Anderson DR, Subrahmanyam K, Workgroup on behalf of the Cl of DM. Digital Screen Media and Cognitive Development. Pediatrics. 2017; 140(Supplement 2):S57-61. 
26. Barr R, Lauricella A, Zack E, Calvert S. Infant and early childhood exposure to adult-directed and child-directed television programming. Merrill-Palmer Q Wayne State Univ Press. 2010;56:21-48.

27. Ozdowska A. Active versus passive screen time for young children. Australas J Early Child. 2012;37:94-8.

28. Linebarger DL, Walker D. Infants' and Toddlers' Television Viewing and Language Outcomes: Am Behav Sci. 2016 .[cited 2020 Jun 22]. Available from: https://journals.sagepub.com/doi/abs/10.1177/0002764204271505

29. Christakis DA, Ramirez JSB, Ferguson SM, Ravinder S, Ramirez J-M. How early media exposure may affect cognitive function: a review of results from observations in humans and experiments in mice. Proc Natl Acad Sci. 2018; 115(40):9851-8.

30. Christakis DA, Zimmerman FJ, DiGiuseppe DL, McCarty CA. Early television exposure and subsequent attentional problems in children. Pediatrics. 2004; 113(4):708-13.

31. Television viewing associates with delayed language development. PubMed - NCBI [Internet]. [cited 2020 Apr 3]. Available from: https:/www. ncbi.nlm.nih.gov/pubmed/18460044.

32. Li C, Cheng G, Sha T, Cheng W, Yan Y. The Relationships between Screen Use and Health Indicators among Infants, Toddlers, and Preschoolers: A Meta-Analysis and Systematic Review. Int J Environ Res Public Health. 2020; 17(19). [cited 2020 Nov 5]. Available from: https:/www.ncbi.nlm.nih.gov/ pmc/articles/PMC7579161/

33. Rosin H. The Touch-Screen Generation: The Atlantic; 2013. [cited 2020 Dec 20]. Available from: https://www.theatlantic.com/magazine/archive/2013/04/ the-touch-screen-generation/309250/

34. Frequency of Parent-Supervised Outdoor Play of US Preschool-Aged Children | Pediatrics | JAMA Pediatrics | JAMA Network. [cited 2021 Jan 16]. Available from: https://jamanetwork.com/journals/jamapediatrics/article-a bstract/1149487

\section{Publisher's Note}

Springer Nature remains neutral with regard to jurisdictional claims in published maps and institutional affiliations.

Ready to submit your research? Choose BMC and benefit from:

- fast, convenient online submission

- thorough peer review by experienced researchers in your field

- rapid publication on acceptance

- support for research data, including large and complex data types

- gold Open Access which fosters wider collaboration and increased citations

- maximum visibility for your research: over $100 \mathrm{M}$ website views per year

At $\mathrm{BMC}$, research is always in progress.

Learn more biomedcentral.com/submissions 